\title{
RAPPERS DO SENHOR: O HIP HOP GOSPEL COMO MOVIMENTO DE AFIRMAÇÃO SOCIAL DE SEGMENTOS MARGINALIZADOS DA JUVENTUDE NEGRA EM MG
}

\author{
Marcelo Ayres Camurça ${ }^{1}$ \\ Tâmara Lis Reis Umbelino ${ }^{2}$
}

\begin{abstract}
Resumo: Este artigo busca enfocar o fenômeno do hip hop gospel como um movimento de afirmação social e de identidade cultural, produzido por jovens negros moradores dos bairros de periferia da cidade de Juiz de Fora - MG. Pertencentes ao grupo "Ministério Galera de Cristo" ligada à igreja pentecostal "Igreja de Cristo", desenvolvem um culto marcado por uma estética de negritude proveniente do rap norte-americano moderno e urbano, e por um conteúdo de denúncia a situações de injustiça social e racismo. Liderados pelo jovem negro alcunhado de Negro Bússola mantém uma rádio comunitária "pirata", atividade não tão de acordo com uma ética rígida pentecostal, mas afinada com o estilo transgressor rapper, como forma de promover uma conscientização dos jovens negros da periferia.
\end{abstract}

Palavras- chave: Juventude, Negros, Periferia, Pentecostalismo, Hip-Hop gospel

\begin{abstract}
This article aims to focus on the phenomenon of the gospel hip hop as a social assertion and cultural identity movement, produced by Afro-descendent youngsters who live in the outskirts of Juiz de Fora - MG. Members of the group "Ministério Galera de Cristo" (Christ's Guys Ministry), linked to the Pentecostal church "Igreja de Cristo" (Church of Christ), they developed a cult marked by a negro aesthetic originating from NorthAmerica's modern and urban rap, and by a content of accusation of situations of social injustice and racism. Leaded by the Afro-descendent youngster nicknamed Negro Bússola (Black Compass), they keep a pirate communitarian radio, activity that does not completely accord to a strict Pentecostal ethics, but close to the transgressor rapper style, as a way to promote the awareness of Afro-descendent youngsters from the outskirts.
\end{abstract}

Keywords: Youth, Afro-descendent, Outskirts, Pentecostalism, Hip-Hop Gospel

1 Docente do Programa de Pós-Graduação em Ciência da Religião (PPCIR) e do Programa de Pós-Graduação em Ciências Sociais (PPGCSO) da Universidade Federal de Juiz de Fora (UFJF)

2 Jornalista e Mestre em Ciências Sociais pelo Programa de Pós-Graduação em Ciências Sociais da UFJF. Professora do curso de Comunicação Social da Faculdade Estácio de Sá Juiz de Fora. 


\section{O HIP HOP GOSPEL}

Um fenômeno que vem despertando atenção, quando se aborda o tema da articulação entre as esferas da juventude, religiosidade e políticas públicas é, sem dúvida, o movimento Hip Hop Gospel. Embora, à primeira vista Hip Hop e Pentecostalismo pareçam forças antagônicas ou dissociadas, o que se percebe é que fruto de dinâmicas sócio-culturais em desenvolvimento no país, uma afinidade eletiva entre ambos vem se firmando, dando início a um movimento que vem modificando a vida de muitos jovens em todo o país.

As semelhanças na postura de combate às drogas e ao álcool e a orientação para uma vida regrada (ainda que entremeada pelo louvor lúdico) e baseada em princípios éticos são alguns dos fatores responsáveis pela aproximação entre evangélicos e rappers. A existência destes pontos de convergência faz com que grupos de Rap strictu sensu tratem, na grande maioria das vezes, os evangélicos do hip hop como "manos". Indicador disto é o fato de que, no ano de 2001, pela primeira vez, o prêmio Hutuz, considerado o maior prêmio de Hip Hop no Brasil, passou a premiar a categoria Gospel. (NOVAES, 2003, p. 28).

Pertença comum à "manos" gospels e não-gospels, o Hip Hop, mais do que uma expressão artística, é, para estes jovens negros de periferia, demonstração de resistência e resgate da própria imagem. Eles explicam que a escolha pelo Rap não foi feita aleatoriamente, pois o ritmo possui um histórico de retratar o cotidiano de violência e discriminação das periferias das grandes cidades. Ao narrar, em suas letras, a realidade dos bairros pobres e seus problemas, os jovens passam a se identificar, vendo nas músicas uma forma de elaborar as próprias experiências vividas. Por isto mesmo, a escolha pelo Rap significa mais do que aderir a um modismo. Implica em um ethos e uma visão de mundo determinada. É uma escolha que passa a interferir no conjunto das práticas e relações sociais, assim como na elaboração simbólica que fazem delas. (DAYRELL, 2005).

A denúncia do preconceito racial é um dos seus temas mais recorrentes, assim como a presença da religiosidade como alternativa, que apresenta "a Palavra" como porta de acesso para uma vida nova e libertação de situações de opressão. Isto como resposta ao senso comum e aos meios de comunicação de massa, para quem o tema da violência está fortemente associado aos jovens, de maneira mais habitual àqueles mais pobres, negros e de sexo masculino (NOVAES \& MAFRA, 1998). Não é de se estranhar, portanto, que as letras dos raps falem da história da escravidão e da luta pela igualdade de direitos entre negros e brancos. 
Há hoje, nas periferias dos centros urbanos do país, toda uma efervescência cultural protagonizada por esta parcela da juventude. Ao contrário da imagem socialmente criada a respeito dos jovens pobres - que os coloca quase sempre associados à violência e à marginalidade -, eles se apresentam como produtores culturais: a música é seu produto mais consumido, em torno da qual criam seus grupos de estilos diversos, dentre eles o rap e o funk (DAYRELL, 2002; 2005). Homóloga a realidade destes jovens negros moradores da periferia, sua representação cultural, formada por quatro elementos, a saber: música, grafite, poesia e dança, apesar de conseguir grande mobilização popular (principalmente nas periferias), ainda não foi reconhecida pelas instâncias do poder público, como um movimento cultural e político que vem promovendo significativas mudanças nestes segmentos. A informação, quinto elemento da cultura Hip Hop, confere destaque para o conhecimento e valorização da cultura negra e sua história e combate ao preconceito contra negros, mulheres e homossexuais. $\mathrm{O}$ estudo deste fenômeno por disciplinas como antropologia e a sociologia ainda é recente, apesar de centros de referência como o NAU, Núcleo de Antropologia Urbana do Departamento de Antropologia da USP, voltado para pesquisa e discussões teórico-metodológicas sobre questões relativas às sociedades urbano-industriais contemporâneas ${ }^{3}$, já haver publicado estudos significativos sobre o tema (SOUZA, J, 2004)

Os grupos juvenis da periferia que concentram esse conjunto de elementos culturais utilizados de forma política e social são denominados "posses". Eles se constituem em associações responsáveis por organizar o movimento e falar em nome dele. Geralmente voltados para o objetivo de atuar em favelas e áreas periféricas em defesa da paz e contra as drogas, estes grupos têm grande aproximação com ONGs, igrejas e instâncias governamentais, sem perder, no entanto, sua autonomia que se expressa em conexões com "redes" internacionais, como também em ligação com o mercado e a midia (que se dá em graus variados de relação entre os grupos).

Para estes grupos de jovens, a possibilidade de viver seu estilo de vida dentro da religião era, até pouco tempo, algo impensável. Acostumados com cultos para os quais, se desejassem freqüentar, precisavam se "travestir" com roupas, cabelos e postura muito diferentes das suas e entoar cânticos que em nada lembram o Rap, esta nova possibilidade de vivência religiosa faz com que grande parte deles se sinta atraída para a nova religião. No entanto, esta ligação não acontece sem que haja uma "negociação" entre a estrutura tradicional destas igrejas evangélicas e seus novos aderentes. Uma das

3 Endereço eletrônico do grupo http://www.n-a-u.org/ 
questões que buscamos compreender é de que forma algumas igrejas evangélicas estão se "flexibilizando" para incorporar a linguagem destes jovens.

\section{PENTECOSTALISMO E PERIFERIA}

O impactante crescimento do pentecostalismo no país, levando em consideração sua penetração nas classes sociais, se mostrou, desde o início, mais forte entre as camadas mais pauperizadas. Uma mensagem que defendia a existência de uma vida melhor, aqui e agora, e a "prosperidade" ao alcance daqueles que almejassem obtê-la, mesmo que de uma forma "mágica", encontrou campo fértil para se desenvolver, principalmente entre os extratos da população mais pobres, marginalizados e menos escolarizados (MARIANO, 1999).

O que não significa, entretanto, que a pobreza seja motivo suficiente para explicar o alto grau de adesão ao pentecostalismo nesta parcela da população. O juízo de que a pobreza e a ignorância são os fatores responsáveis pelo crescimento pentecostal entre as camadas subalternas foi, de certa maneira, incentivado pela mídia na sua cobertura muitas vezes tendenciosa das noticias envolvendo a relação entre fiéis e pastores. Também aparece em membros dos grupos mais intelectualizados da sociedade para quem estas igrejas não passam de exploradoras da boa vontade de um povo ignorante, que não teria condições e informações suficientes para fazer uma escolha religiosa acertada. As principais críticas direcionadas às igrejas pentecostais se baseiam, fundamentalmente, no pedido de donativos, feitos, com o que julgam ser uma maneira inescrupulosa pelos pastores, e nas promessas de "curas" e "milagres" de todo tipo por parte destes, esquecendo-se, de todo um processo de eficácia simbólica produzido pelos rituais desenvolvidos nestes templos, que - a despeito de avaliarmos a intencionalidade de suas hierarquias - fornecem ao indivíduo um sentido para sua vida, e partir daí, situações de fato de reversão da miséria (MARIZ, 1996, p.169-189).

O que os críticos esquecem é que, para muitos destes fiéis, ao contrário do que acontece em diversos outros setores de sua vida, nos quais são geralmente o "lado mais fraco", nessas igrejas são colocados na posição de alguém que pode decidir, ou a quem é solicitado algo. Em seu cotidiano, estas pessoas são submetidas a uma condição de subalternidade e de degradação social como falta de saneamento básico, condições de moradia aviltantes, falta de escolaridade, etc, fato que, inevitavelmente, acaba gerando entre elas um sentimento de baixa auto-estima, exclusão e medo. Sensação diferente do que é experienciado nos cultos religiosos pentecostais. "Essa mensagem do 
pentecostalismo sobre a contemporaneidade dos dons devolvia aos pobres um sentimento de posse exclusiva do próprio Deus." (OLIVEIRA, M., 2004, p. 49).

Neste ambiente, além de serem recebidos como alguém "importante", o que ajuda a restabelecer sua dignidade, pois é justamente no ato de pagar os dízimos e realizar ofertas, que estes pobres, excluídos, percebem-se capazes de construir algo, o que configura uma positividade nas relações de poder em que estão envolvidos. Afinal, dá quem pode! "Como o pentecostalismo, em geral, não dá aos pobres, mas pede deles, faz com que estes pobres deixem de ser subjetivamente pobres" (MARIZ, 1996, p. 183). Apesar de terminarem o culto com menos dinheiro no bolso, eles voltam para casa, também menos miseráveis enquanto sujeitos.

Desta forma, a preocupação com o destino que tomam as doações feitas por eles é mais importante para aqueles que estão fora desta sociabilidade. Para os pentecostais é o ato em si da doação que deve merecer maior atenção onde, de fato, reside sua fortaleza. Ao tomarem esta iniciativa no espaço eclesial ganham confiança para estendê-la à vida cotidiana, revestindo seus atos profanos desta (auto) confiança "sagrada" conseguindo assim reverter situações de alcoolismo, banditismo e assegurando progresso em sua vida financeira e social. Desta forma a condição de pobre, e o desejo de libertar-se desta condição, se encontram simbolizados no rito, na linguagem, na concepção de Deus e na própria formação das Igrejas Pentecostais.

Uma destas é a "Igreja de Deus" fundada nos Estados Unidos em 12 de maio de 1955. Por ser uma igreja situada no que se convencionou chamar de "segunda onda" na história do pentecostalismo brasileiro, a "Igreja de Deus" teve como característica marcante a introdução nos cultos de recursos tecnológicos modernos como a guitarra elétrica gerando um conseqüente clima de informalidade e sensualidade em um outrora ambiente de contrição e ascese (MAFRA, 2001, p.35). Desta forma, aliando emotividade, promessa de "cura divina" e reversão de uma situação de dificuldades a um estilo descontraído de pregação, através da música com seus "corinhos alegres e contagiantes" (MAFRA, 2001, p.35), estas igrejas poderão se adequar a uma "dinâmica de cultura de massas" (MAFRA, 2001, p.36), que sem dúvida protagonizará os experimentos atuais levados a cabo pelos jovens da "Galera de Cristo".

A "Igreja de Deus" em Juiz de Fora, localizada no bairro de periferia Ipiranga, é o berço deste movimento de hip hop gospel entre jovens pobres e negros, intitulado "Ministério Galera de Cristo" e, segundo os jovens que fazem parte do movimento, a criação deste Ministério só foi possível através da 
aceitação dos "rappers convertidos" pelo pastor José Berto da Silva, 58 anos. Ordenado há mais de 24 anos, o pastor veio de Belo Horizonte para Juiz de Fora em 1991, ajudar, como mestre de obras, na construção de uma igreja no bairro Nova Era, zona norte da cidade, onde sua irmã era pastora. Durante a construção ele, que já era evangélico e pastor em Belo Horizonte, conquistou o respeito da comunidade que o convidou a assumir a igreja local. Alguns anos mais tarde a igreja se tornaria a instância onde o movimento Hip Hop Gospel em Juiz de Fora através do "Ministério Galera de Cristo" germinaria e se disseminaria.

\section{MINISTÉRIO GALERA DE CRISTO}

O "Ministério Galera de Cristo" é formado por jovens, evangélicos, negros, em sua grande maioria, e moradores da periferia da zona sul de Juiz de Fora. Aqui, acreditamos ser válido enfatizarmos melhor o sentido do que é ser jovem para o grupo em questão e destacar que, do ponto de vista antropológico, é o contexto sócio-cultural o responsável pela construção de suas representações de juventude, definidas, muitas vezes, pela posição social do jovem e pelo tratamento decorrente desta posição. Importante fase da vida, na sociedade moderna, embora haja uma flutuação nos limites de idade que compõe essa faixa geracional, a juventude é compreendida como um tempo de construção de identidades e de definição de projetos de futuro (NOVAES, 1998).

A maior parte dos integrantes do "Ministério Galera de Cristo" convive, diariamente, com a violência presente na periferia, baixa escolaridade e necessidade de trabalhar cada vez mais cedo para ajudar no sustento da família. Para estes jovens as experiências nos grupos de Rap evidenciam um dos poucos espaços nos quais podem vivenciar experiências cruciais na construção de uma identidade juvenil. É um espaço singular na construção de uma determinada identidade coletiva enquanto jovens, uma expressão particular da própria condição juvenil das camadas populares (DAYRELL, 2005). Para quem teve que "crescer" rápido demais, a possibilidade de participação em uma "posse" de Hip Hop pode significar a chance de desenvolver atividades não rotineiras e obrigatórias, se vestir com outras roupas que não os uniformes de ofice-boys, com os quais passam os dias, e dançar, cantar e usufruir da descontração que caracteriza o estilo de vida jovem.

A facilidade de adesão e falta de critérios rígidos para fazer parte da "Galera de Cristo" faz com que o número de participantes seja de difícil mensuração e, por isto mesmo, haja grande dificuldade em classificar estatisticamente, em termos etários, de sexo e cor, os integrantes do 
Ministério. No entanto, quando há reunião dos membros da Galera para orar ou dançar Hip Hop Gospel fica mais fácil traçar um perfil dos integrantes do grupo: eles são negros, pobres, em sua grande maioria homens e com idades variando dos doze aos trinta e poucos anos. No entanto, todos se referem aos outros, e a si próprios, como jovens e esta atitude não é muito difícil de ser compreendida: "Em um contexto social que os reduz a jovens proibidos de ser (...) o estilo de vida Rap é uma denúncia e uma reivindicação do direito à juventude" (DAYRELL, 2005).

Embora estejam compreendidos em uma faixa etária bastante alargada, esteticamente são muito parecidos: usam calças ou bermudas largas para facilitar a dança e camisas grandes e coloridas, fazem, em sua grande maioria, referências a times de basquete norte-americanos. O tratamento dispensado aos cabelos é um aspecto que merece especial atenção, pois fazem do penteado uma forma de expressar seu orgulho de "ser negro". Estão, invariavelmente, com penteado afro ou com a cabeça raspada, coberta por boinas ou bonés multicoloridos.

A sensação que temos é de que estes rapazes, obrigados a crescer rapidamente para ajudar a família e criar a sua própria que constituem cada vez mais cedo, aproveitam a estética da cultura Hip Hop para viverem mais intensamente sua "juventude", dançando, cantando e vestindo suas bermudas e roupas coloridas. Para estes jovens, que vivem em situação de extrema pobreza - muitas vezes os vimos comentando que não puderam ir a determinado evento por não ter um vale-transporte para pegar o ônibus - convivendo dentro de casa, além da penúria econômica, com situações de alcoolismo e tráfico de drogas, a igreja surge como possibilidade de dar novo significado a esta existência:

A religião, enquanto sistema de símbolos pode dar à existência um sentido que permita suportá-la a despeito das perplexidades, do sofrimento e da injustiça. $\mathrm{O}$ renascimento proporcionado pela conversão é o início de uma contínua reconstrução do passado: onde antes só havia caos e confusão, agora passa a haver - a despeito das provações e mesmo através delas - o cumprimento de um plano de Deus, cujo significado imediato (...) pode nos escapar, mas logo irá revelar-se. (SOUZA, 2001, p. 179).

\section{NEGRO BÚSSOLA}


É impensável tentar compreender o "Ministério Galera de Cristo" sem conhecer a história de seu fundador. Nascido há 32 anos, filho de pais pobres e terceiro filho de uma família de quatro irmãos (dois homens e duas mulheres), e atualmente casado com a filha do Pastor José Berto, Negro Bússola nem sempre foi motivo de orgulho para a família. Não foram raras as vezes em que, sentindo vontade de estar na moda, "desceu" para a parte nobre da Zona Sul para "tirar o tênis de um playboy". Nesta época, o evangelho foi apresentado a ele pela primeira vez, por um freqüentador da igreja evangélica do bairro, ao encontrá-lo fumando maconha.

Ele disse pra mim: "Chegue no espelho e veja quem é você!" Mas não tive como falar quem sou eu porque eu não tinha nada construído. Então foi preciso ver que eu era nada para poder construir alguma coisa, minha verdadeira identidade no convívio social. Aí comecei a pensar: "o eu é quem arruma um dinheiro em coisa errada e gasta em coisa errada, arruma dinheiro em assalto e roubo e gasta em droga, bebida e mulher. Será que eu estou certo?" E vi que eu tinha que dar uma virada. (Negro Bússola)

Mas, a "virada" demorou seis anos para acontecer. Aos dezesseis, a maconha não o satisfazia mais e nem os tênis eram os alvos preferenciais de furto. Em seus piores dias, chegava a passar a maior parte do tempo fumando crack. E foi justamente em uma destas "viagens" em um campo de futebol abandonado, no centro do bairro, após ter participado de um assalto, que dois policiais militares o encontraram. Um deles queria executá-lo ali mesmo e, ainda hoje, Bússola diz poder ouvir as palavras ditas pelo outro: "É apenas mais um preto, pobre da periferia. Mata ele!" O pavor tomou conta dele, que acredita ter sido salvo por um milagre, isto o fez prometer que, caso sobrevivesse àquela situação, abandonaria a vida do crime. Os policiais mudaram de idéia e ele de vida. Acredita que foi salvo pela intercessão de Deus, que tem um claro propósito para sua vida.

Desde seu surgimento até os dias de hoje, a "Galera de Cristo" continua tendo nele, que passou a ser conhecido por Negro Bússola, seu "norte". É ele o único a dar entrevistas e representar o Ministério, embora algumas vezes outros jovens o estejam acompanhando.

Se, por um lado, determinação e vontade de mudar são características marcantes na personalidade de Negro Bússola, por outro, a despeito da capacidade de mobilização dos jovens na "Galera", ele afirma não conseguir interiorizar ainda esses valores mais profundos nos seus seguidores. A todo o momento destaca que seu trabalho é solitário e que apenas poucas pessoas são capazes de "alcançar" seus reais objetivos. Para ele, os outros jovens se limitam a segui-lo e cumprir 
suas ordens sem entender a importância destas mudanças para o projeto maior que pretende implementar na sociedade.

Em sua avaliação, a baixa escolaridade, desestrutura familiar e a ausência de perspectiva não podem justificar o desinteresse dos jovens da periferia pela mudança do rumo de suas vidas. Há que se ter muita força de vontade e se deixar iluminar por Deus, ou como ele prefere: possuir "predestinação". Bússola define a si mesmo como um "Anjo Negro", homem de muita sorte e que, por isto mesmo, tem um poder de compreensão mais aguçado do que o dos demais. "A experiência direta com o sagrado, a crença num contato direto com Deus, também rompe o sentimento de impotência e alimenta a auto-estima dos que se sentiam fracassados" (MARIZ, 1996, p. 175). No seu entender, a força para a mudança não foi apenas mérito seu, pois ele já nasceu para cumprir este "plano divino".

Para não deixar o cargo desocupado, caso ele venha a faltar, confidencia que está "treinando" um substituto, Rafael, para ser o vice-presidente da "Rádio Guetto" e assumir o "Ministério Galera de Cristo". Enquanto este tempo não chega, tenta manter os sonhos e a família, o que, segundo ele, não é uma tarefa fácil.

Durante as conversas Bússola cita com freqüência Martin Luther King e Nelson Mandela. Perguntamos como tomou conhecimento destas personalidades e ele explica que conheceu Luther King e outros ativistas negros através das letras do Rap. "Eu ouvia o cara dizer um nome destes no meio da letra da música e ia procurar saber quem eram estes caras e o que mais eles tinham dito". Apesar de ter concluído o segundo grau, faz questão de dizer que muito do que aprendeu se deve ao Rap. Para tornar seu sonho realidade, Bússola passa grande parte dos seus dias fazendo os serviços de pedreiro, bombeiro, eletricista e o que mais for preciso. Mas, ainda assim, pretende usar outros artifícios para conseguir "chegar ao poder" e concretizar seus ideais. Um de seus sonhos é cursar faculdade de Jornalismo e, desta forma, "ser mais respeitado pelas pessoas".

\section{A ATUAÇÃO DO “MINISTÉRIO GALERA DE CRISTO”}

Após os primeiros contatos nas portas dos bailes para sua conversão e socialização no grupo jovem evangélico, os jovens passam também a freqüentar os cultos da "Igreja de Deus" no bairro Ipiranga. Surgiu aí o estranhamento. Na igreja, frente a frente, de um lado os rappers recémconvertidos, com seu visual exuberante e gingados no andar e, de outro, os crentes "tradicionais", com seus ternos escuros, saias compridas e postura rígida, por dentro e por fora. O resultado: envio de 
reclamações para a direção da igreja por parte dos fiéis tradicionais e incômodo de ambas as partes.

Foi preciso tempo para que, como acontece hoje, os jovens pudessem se apresentar durante o culto lotado e contar com a participação da grande maioria dos presentes, cantando e dançando. Para garantir que os antigos fiéis não se sentissem desmerecidos e os novos convertidos discriminados, o Pastor precisou tomar medidas estratégicas. Uma delas está relacionada às obras da igreja que estão sendo finalizadas e irão garantir espaço para todas as formas de expressão cultural. No corredor lateral, ao lado do quadro de avisos "convencional" com cartazes de papel, os grafiteiros poderão expor seus trabalhos, utilizando latas de spray e muita imaginação, Tudo para que todos se sintam "em casa".

Ainda assim, o pastor admite que, muitas vezes, precisa administrar conflitos e preconceitos arraigados nas atitudes e comportamentos dos fiéis. No entanto, destaca que, quanto ao preconceito racial, este "é quase zero" dentro de sua igreja e das evangélicas em geral E como comprovação lembra a existência de lideranças negras evangélicas em diversas partes do país e o fato de haver pastores negros no conselho executivo da "Igreja de Deus". Opinião que parece ser confirmada pelas estatísticas que mostram a presença expressiva dos negros entre as fileiras evangélicas. De acordo com as enquetes há muito mais negros evangélicos do que negros espíritas, umbandistas, do que negros no candomblé, ou em outras religiões e negros que se declaram sem religião. Dados indicam que a taxa de negros pentecostais $(14,2 \%)$ é mais alta que a de pardos pentecostais $(10,8 \%)$ e brancos pentecostais $(9,1 \%)$ e amarelos pentecostais $(6,3 \%)$ (PIERUCCI, 2006). Tudo isso, leva-nos a crer, que as igrejas e movimentos evangélicos podem vir a se converter em nichos de luta pela "identidade negra", a maneira de como foi o Islã para os Estados Unidos na década de sessenta, embora aqui, o enfrentamento seja mais simbólico e cultural que ativismo político e militante como para o caso norteamericano citado.

Apesar de haver, na opinião de alguns fiéis mais antigos da "Igreja de Cristo" a necessidade de manutenção da austeridade nos costumes da membrezia, não há nos estatutos da igreja qualquer restrição quanto à liturgia nos cultos. Foi nesta brecha que o "Ministério Galera de Cristo" encontrou espaço para se expressar. Espaço, inclusive, que já foi ocupado por manifestações semelhantes nas origens do pentecostalismo quando estava intimamente ligado aos clamores de segmentos negros norte-americanos por justiça social. "Os cânticos conhecidos como negro spirituals traduziram protestos contra a injustiça social, o racismo e outras formas de marginalização" (CAMPOS, 1996, p. 58). Na avaliação do articulador da Teologia Negra da Libertação nos Estados Unidos, James H. 
Corne, os spirituals podem ser definidos como a forma encontrada pelos negros para expressar a nãoconformidade com o racismo e a escravidão.

No entanto, este passado marcado pelas manifestações de uma "identidade negra" no movimento evangélico, não evitou dentro da igreja, criticas e reprovações às presenças dos "rappers do Senhor", com seu visual agressivo e letras questionadoras. As críticas, no entanto, vieram dos membros mais antigos da igreja, para os quais o espaço sagrado do templo estava sendo profanado. Reclamações foram enviadas às instâncias superiores da instituição, mas não surtiram o efeito desejado e o trabalho junto ao ministério dos rappers continuou dando mostras de que os movimentos religiosos são também processos sociais dinâmicos e, uma vez instaurados, seguem seu processo, abandonando em sua trajetória antigas características e assimilando outras novas que possam facilitar a sua expansão e dinâmica (CAMPOS, 1996).

Mesmo declarando que, na primeira vez que teve contato com o Funk e o Hip Hop, não gostou, o pastor José Berto, após assistir uma cena de adolescentes cheirando cocaína em um banco de praça em plena luz do dia, percebeu que era fundamental aprender a falar a língua deles para resgatá-los e fazê-los "mudar de vida".

As dificuldades de aproximação aconteceram, dentre outros motivos, pela imagem de rigidez que os evangélicos granjearam, o que fez com que os adolescentes os repelissem de antemão. Foi só contando com a constituição do "Ministério Galera de Cristo", que se assemelhava, no modo de vestir, tipo de música ouvida e "dialeto" falado com os rapazes que se drogavam na praça, ou cometiam pequenos delitos na vizinhança, que a igreja conseguiu converter muitos destes jovens.

O Pastor José Berto procurou saber mais sobre o Hip Hop e, ao descobrir que após terem trocado as brigas reais de gangue por disputas rituais de dança de rua, a vida de muitos jovens norteamericanos havia mudado, resolveu abrir as portas da igreja para que, uma vez por semana, aos sábados, fosse realizado um culto apenas para os rappers. A grande maioria ainda era formada por não convertidos que se aproximavam primeiro, por curiosidade e pouco tempo depois acabavam aderindo à igreja.

Com o som no último volume, danças ritmadas e letras que exaltavam o Senhor, dezenas de jovens negros, pobres e marginalizados chegavam pontualmente, vindos de diversas periferias da cidade, para participar do culto. No entanto, alguns meses depois, as obras de ampliação na igreja acabaram extinguindo o culto exclusivo para rappers e suas apresentações passaram a acontecer 
durante os cultos "normais".

Em um cenário de alargamento do culto e louvor para além do templo, surgem as "festas" (PINHEIRO, 2003) e não há mais dia ou hora marcados para rezar, pois a religiosidade se encontra disseminada nos encontros de jovens, bailes de Hip Hop, forrós, cinemas, rádios, televisão, jornais e/ou, cada vez mais constantemente, nas salas de aula. A religião está presente no dia-a-dia das pessoas que se sentem cada vez mais "confortáveis" para experimentar sua nova condição de fiéis. Não é mais preciso trocar de roupa, cortar o cabelo, mudar as "companhias" ou locais que freqüentam para ser aceito como "religioso". E, mais do que isto: é possível assumir, sem medo de censura, a busca por ascensão social e os benefícios trazidos por atividades como as desenvolvidas pelo "Ministério Galera de Cristo", em cultos onde dançam e cantam hip hop, enquanto imitam coreografias similares às que faziam nos bailes funks, antes da conversão, ou nas festas de Rap que freqüentam atualmente. Comportamento que seria certamente impensável até duas décadas atrás (MARIANO, 1999).

Para tentarmos compreender o ethos do "Ministério Galera de Cristo", podemos utilizar-nos do conceito de "comunidade imaginada" de Brigit Anderson. De acordo com esta definição, a idéia de comunidade é formada à medida que alguns sujeitos imaginam compartilhar os mesmos símbolos e mitos de origem que organizam as representações das fronteiras do que é o "nós" e o "outro" desta comunidade. (LOPES, 2007). Atualmente, esta definição é utilizada por muitos autores para pensar grupos sociais como as comunidades étnicas e/ou religiosas. Nestes lugares (simbólicos e reais) se expressam valores e posturas ligadas à questão da identidade étnica/ negra, sem que obrigatoriamente estas identidades estejam circunscritas a critérios fixos e rígidos como, origem, raça etc. Funciona aqui a auto-atribuição identitária (CARDOSO DE OLIVEIRA, 1976). Há cada vez maior possibilidade de re-interpretações sobre, por exemplo, como devam ser vividos os valores do que se possa chamar negritude. Cada vez mais, a visão que ligava de maneira inexorável os valores relativos à negritude a uma "matriz africana" com todo seu corolário de imagens e símbolos marcados por um tradicionalismo "de raiz" está dando lugar a outras, como a manifestação da cultura Hip Hop e seus elementos nitidamente ligados ao movimento negro norte-americano, e seus conteúdos modernos, urbanos e pop (CUNHA, 1993; PINHEIRO, 2003; 2006).

\section{GUETTO NO AR}


$\mathrm{Na}$ tentativa de denunciar a situação de miséria e exclusão a que são submetidos e promover a conscientização e evangelização da comunidade na qual estão inseridos, os membros do "Ministério Galera de Cristo" resolveram fundar, ainda que clandestinamente, e em desacordo com as rígidas normas de comportamento pregadas pelas igrejas evangélicas, se aproximando mais da cultura underground vivenciada pelos rappers, uma emissora de rádio batizada como Guetto FM, que tem como slogan "a comunidade agora tem voz ativa".

Nos microfones atuam locutores que, apesar de não terem passado por cursos de capacitação, são da própria comunidade e procuraram à emissora em busca de oportunidade. A rádio entrou no ar pela primeira vez no dia 26 de agosto de 2006, utilizando-se, sem autorização legal, da sintonia 106,5 FM. Tem o estúdio situado no bairro Santa Efigênia, em local revelado para poucos, e potência de 100 watts, quatro vezes superior à autorizada para as rádios comunitárias. Por contar com esta potência, alcançava diversos bairros da região como Santa Luzia, Ipiranga, Vale Verde, Sagrado Coração de Jesus e Jardim Gaúcho.

A emissora funcionava numa pequena casa de três cômodos, alugada e "preparada" para funcionar como emissora. Logo na entrada, uma parede inteira coberta com fotos de membros do Ministério com importantes figuras da comunicação, das artes e do cenário político local e nacional, como Gilberto Gil, MV Bill e Patrus Ananias. Ao lado das fotos, diplomas e certificados de participação aos membros do "Ministério Galera de Cristo" em seminários, cursos e eventos ligados à cultura na cidade.

Tecnologicamente a emissora contava com uma pequena mesa de som, dois ou três microfones e um computador em que grande parte das músicas ficava arquivada, além dos anúncios feitos por encomenda para os comerciantes (donos de padaria, açougues e pequenos empreendimentos) do bairro e "programetes" "baixados" gratuitamente dos sites do Governo Federal com temáticas relativas à saúde, educação e segurança. Enfim, uma forma "ilegal" que dissemina mensagens "legais" e até "oficiais" dentro de um conteúdo "politicamente correto".

Apesar de não contar em seu quadro de funcionários, com profissionais da comunicação regularmente capacitados, a rádio se manteve funcionando até maio de 2007 quando, após ter sido denunciada como "rádio pirata", temendo sanções legais, foi tirada do ar temporariamente pela

Emissoras de rádio não-autorizadas recebem o nome de pirata, por associação com um fenômeno inglês que tem a ver com o monopólio de um país (Grã-Bretanha) no período no qual eram proibidas veiculações de propagandas em rádio. Os navios, com bandeiras negras, que lembravam os piratas, transmitiam de maneira irregular, na costa da Europa, fora 
própria equipe da emissora.

Na rádio, coordenada por um evangélico há espaço, ao lado dos pastores e membros da "Galera de Cristo", para um locutor assumidamente homossexual apresentar programas de fofocas da televisão; para uma estudante de jornalismo de uma faculdade particular estagiar e para tantos outros homens e mulheres inexperientes enquanto locutores e comunicadores radiofônicos. Aqui, o propósito comunitário sobrepujando tanto uma rígida ética evangélica quanto um instrumental técnico competente da comunicação.

Após quase oito meses fora do ar, no início de 2008, ainda sem autorização, a Rádio Guetto voltou a funcionar em novas instalações de maneira clandestina por não ter obtido a legalização. Este é, inclusive, um processo que envolve altos gastos e muita burocracia. Para obtenção de um canal para funcionamento de uma emissora de rádio educativa é preciso que o interessado verifique, no Plano Básico de Distribuição de Freqüências, se há um canal educativo disponível para a localidade onde se quer instalar a emissora. Caso não haja, é preciso encaminhar um pedido para que o Ministério das Comunicações faça uma análise, junto a uma proposta de viabilidade técnica que deve ser elaborada por um engenheiro habilitado, demonstrando que é possível a inclusão do novo canal de transmissão Em Juiz de Fora várias emissoras esperam pela concessão do governo para funcionar legalmente.

\section{PROMOÇÃO DA CIDADANIA}

Outro projeto conquistado com o concurso do "Ministério Galera de Cristo" é a "Casa de Cultura Evaílton Vilela", centro de referência das mais diversas manifestações artísticas de sua comunidade. A instituição está sendo montada em uma casa que estava abandonada e foi alugada de um morador do bairro. Lá estão programadas para acontecer aulas de informática gratuitas, cursos prévestibulares, também de graça, e reuniões de Alcoólicos Anônimos, além de aulas de dança e música.

A inauguração "Casa de Cultura Evailton Vilela" contou com uma série de eventos. O primeiro deles aconteceu no dia 19 de abril e contou com a apresentação de bandas locais e de renome nacional, como as da Igreja do Evangelho Quadrangular dos bairros Santa Efigênia, Sagrado Coração de Jesus e Santa Luzia, Igreja de Deus no Brasil do Bairro Ipiranga e Igreja Apostólica do Bairro Santa Luzia. No dia 20, domingo, das $9 \mathrm{~h}$ às $17 \mathrm{~h} 30$ aconteceram na praça principal do bairro, Rua de Lazer; corte de cabelo, aplicação de flúor, confecção carteiras de identidade para os jovens, atendimento social da 
Prefeitura e apresentação do "Grupo de Percussão e Grafitti Programa nos Trilhos da Paz". A festa foi até dia 21 quando grupos de Street Dance, Hip-Hop, Ong Axé Criança e escola de samba mirim fizeram suas apresentações. O evento contou ainda com apresentação de DJ's, roda de capoeira com grupos locais e convidados.

Apesar de não ser um espaço estritamente religioso, há a proposta de oferecer aos atendidos a oportunidade de mudar de vida. Entra aí a "Igreja de Deus no Brasil" como instrumento de evangelização para uma população que, além de conviver com a pobreza, falta de estudo e violência, precisa ainda lidar com a desestrutura familiar. "É filha que chega grávida de pai, pais que estupraram filhas, irmão que sodomizou o próprio irmão", explicita o pastor José Berto. Ir à igreja, para estas populações, sobretudo, freqüentar seus cultos (mesmo que estes estejam cada vez mais imbricados com eventos profanos), significa que neles é que se reconstrói o significado de tantas vidas ameaçadas pelo caos, paralisadas pela perplexidade, mergulhadas na dor, acossadas pela iniqüidade e pela violência (SOUZA, M., 2001).

Além do reconhecimento social, a capacitação para trabalhar com os equipamentos de som, as atividades do Centro também proporcionam a estes jovens a chance de atuarem como DJ's e locutores em Rádios Comunitárias e "piratas" que crescem de maneira significativa nas periferias das cidades. Nestes locais de trabalho encontram o que buscam de maneira incansável: a chance de serem ouvidos. Lá, com sua eventual deficiência de vocabulário, baixa escolaridade, mesmo que registrem passagens pela polícia, problemas familiares, sendo negros e pobres, terão a chance de expressar sua opinião e serem reconhecidos em sua comunidade. "O rap, por intermédio dos shows, é um meio de articularem uma auto-imagem positiva, uma forma de se afirmarem como "alguém" numa sociedade que massifica e os transforma em anônimos." (DAYRELL, 2005, p. 107).

Os microfones das Rádios Comunitárias e "piratas" funcionam como espaço de construção de uma identidade fragmentada e fragilizada pela constante invisibilização promovida pelos veículos de comunicação de massa, do qual inclusive são críticos afiados. Tendo despontado na mídia enquanto os agentes responsáveis pelos problemas como delinqüência, ócio, violência e irresponsabilidades, estes jovens das classes populares são os mais atingidos pelos efeitos da degradação social (ALVIM; PAIM, 2000).

Para os entrevistados da rádio comunitária, muitos dos problemas enfrentados hoje pela juventude, negra e pobre é fruto da falta de informação e constante "massacre" da auto-estima que se 
repete a cada dia nos comerciais, novelas e filmes em que o ideal de beleza e de profissionais bemsucedidos não se assemelha em nada ao deles (GOMES, 2002). A ausência ou distorções da imagem dos negros nos meios de comunicação é vivida por eles como uma forma de violência extremamente dolorosa, cruel e prejudicial, pois sem referenciais positivos, o negro, enquanto grupo racial, simplesmente deixa de existir. Não é por acaso que são poucos os negros que se reconhecem como negros no Brasil (QUINTÃO, 2001). A todo o momento ressaltam que se sentem órfãos de ídolos e modelos aos quais seguir e destacam que a situação dos moradores da periferia seria muito melhor se pudessem ter acesso aos veículos de comunicação e de fato dizerem quem são. Os meios de comunicação hegemônicos ao divulgarem a imagem estereotipada de jovens suburbanos como ameaçadores e envolvidos em crimes, induzem o público a um tipo de representação sobre os jovens das classes populares. Mesmo tendo consciência de que não se pode atribuir exclusivamente à mídia a responsabilidade pelo modo como estas notícias são encaminhadas, já que o público estabelece com elas um consumo voraz, é no campo da mídia que elas se tornam espetaculares (ALVIM; PAIM, 2000).

Já que a concessão de um canal de TV é praticamente impensável para os grupos populares, que os jornais e revistas não atingem a população analfabeta ou pouco acostumada à leitura, a saída encontrada por eles é a abertura de rádios e o Rap, instrumento de denúncia, formação e informação de grande parcela destes jovens.

Um exemplo de Rappers que atuam com o claro intuito de informar estes jovens e os conscientizar da situação em que vivem é o Racionais MC's, grupo que se tornou referência para um público jovem pobre tanto do circuito leigo quando evangélico. É de conhecimento de todos no cenário musical as histórias de que os membros do grupo, com destaque para Mano Brown, o mais popular dos Racionais, não fazem concessões para grandes emissoras de televisão ou programas dominicais de audiência estrondosa. Só falam quando querem e com quem querem, postura que desperta nos jovens "sem voz" da periferia a chance de se imaginarem negociando "de igual para igual" com o "sistema".

A noção de "sistema", que é muito utilizada por eles, possui uma multiplicidade de sentidos. Pode referir-se ao sistema repressivo, principalmente à polícia, mas também é utilizada no sentido das camadas 
dominantes, ou na sociedade em geral, principalmente quando criticam os preconceitos e estereótipos que sofrem como favelados. A "arma" aqui pode ser vista como o domínio da palavra, por meio da qual podem difundir uma leitura própria da realidade, diferente das versões dominantes, que só “iludem a população". 'Repar' é um instrumento de luta" (DAYRELL, 2005. p. 106).

No entanto, a grande oposição/negociação desta relação mídia x Racionais repercute justamente através destes mesmos veículos de comunicação nos quais foi criada a "aura" de inacessíveis e a qual devem grande parte do respeito com que são tratados no cenário do Rap Nacional. Mesmo sem participar dos aclamados programas de auditório ou posarem para capas de revistas, eles conseguem reunir centenas de milhares de jovens em seus shows, sem contar o fato de que "o CD Sobrevivendo no Inferno vendeu 200 mil cópias em duas semanas. Em 15 dias passou a ocupar lugar de destaque nas lojas de todos os shoppings do país” (NOVAES, 1999).

As letras deixam claro que há circulação de informações. Eles usam estatísticas, falam do IBGE, falam de livros, são assediados por grupos políticos que falam de Marx, têm uma página na internet, fazem parte de uma rede mundial de manos, fazem suas viagens internacionais. (NOVAES, 1999, p. 85)

E apesar de não se apresentarem como pertencendo a uma religião específica, as letras de suas músicas estão impregnadas de referências à Bíblia e a normas de conduta que visam redimir seus jovens ouvintes.

A música dos Racionais também se faz presente durante uma das principais atividades desenvolvidas pelo "Ministério Galera de Cristo": o "Projeto Café com Hip-Hop" promovido com regularidade no Centro Cultural Bernardo Mascarenhas em Juiz de Fora. Durante o "Café com Hip Hop" jovens de diversas partes da cidade se reúnem para apresentar trabalhos que vem sendo feitos junto às comunidades onde vivem. Nota-se a grande presença de jovens DJs dispostos a apresentar seu trabalho em busca de novas oportunidades de emprego. Como mostrou Jane Souto para o caso do funk (SOUTO, 2003,) o Hip Hop também ampliou o mercado de trabalho para os jovens oferecendo a eles perspectivas de trabalho de mais prestigio que as funções comumente desempenhadas por jovens de periferia. 
Ao som dos Racionais, em um canto do salão, os dançarinos, que em breve começarão sua apresentação, fazem exercícios de aquecimento sob olhares atentos dos presentes. A arquibancada tem apenas seis degraus de aproximadamente 10 metros de largura, mas já começa a ser ocupada pelos estudantes que estão participando do evento pela primeira vez e pelos mais ansiosos que chegaram com uma hora de antecedência. Apesar do clima "festivo", o ambiente não lembra um baile ou uma boate, pois o local onde ele ocorre é uma sala onde acontecem exibições de filmes e peças de teatro em um Centro Cultural. No local não há canhões de luz, espelhos ou fumaça. O que favorece, acreditamos uma postura mais "contida" dos presentes.

\section{O PODER DE TRANSFORMAÇÃO DO HIP HOP GOSPEL}

Através do Hip Hop, já antes de sua conversão ao Evangelho, estes jovens tinham a chance de "vomitar" os preconceitos aos quais são diariamente submetidos: a falta de condições dignas de habitação, de emprego, a baixa escolaridade e sua luta para expressar sua vontade de crescer, se expressar, existir e ganhar visibilidade. A tomada de consciência torna muito deles contestadores agressivos, mas outros, devido a também influência religiosa, tornam-se pregadores. Com o Evangelho na ponta da língua, versam, cantam, rodopiam pelo chão e "grafitam" em paredes, para mostrar à sociedade que outra realidade é possível.

É justamente através da vivência religiosa, como evangélicos, que eles têm conseguido construir sua identidade. Em templos, que não precisam ser necessariamente de uma igreja específica, vimos que jovens da "Igreja de Deus no Brasil", mas também da "Casa da Bênção" e outras igrejas, freqüentarem os cultos uns dos outros sem qualquer constrangimento ou mal-estar.

Prova disto é a formação do "Ministério Galera de Cristo", em Juiz de Fora, e do "Provérbio X”, em Brasília, que contam com jovens vindos das mais diversas denominações evangélicas. Este é um fator que flexibiliza uma das características marcantes das igrejas evangélicas tradicionais, o de considerar o "mundo" como o lugar do pecado e de exercer uma intolerância para com estas formas modernas de comportamento do lazer e divertimento como o Rap e do Hip Hop.

Se haviam semelhanças de princípio que aproximavam evangélico-pentecostais dos rappers, como a condenação ao uso de drogas e bebidas alcoólicas e valorização de uma vida regrada e norteada por firmes condutas éticas, as diferenças entre eles também saltavam aos olhos. Os antigos fiéis tiveram então, de passar a se acostumar com um "irmão" vestido com bermudas largas, cabelo 
black power, correntes e anéis, além - claro - dos indefectíveis tênis coloridos. Configura-se patente, então a existência de uma transformação acontecida nos seus padrões éticos e estéticos. O pentecostalismo atual abandona gradativamente as exigências comportamentais rigorosas e adota um estilo mais leve, que permite a cada individuo a responsabilidade - e o direito - de equilibrar seus desejos pessoais à disciplina e aos padrões éticos de sua religião.

Ao conversarmos tanto com um pastor da nova geração como Isaías Jr., vocalista do Provérbio $\mathrm{X}$, quanto com o pastor José Berto, representante da igreja de um tempo em que os costumes eram outros, ficou evidenciada a importância da postura do líder religioso para facilitar esta aproximação entre novos e antigos evangélicos. Foi a dimensão do louvor, presente nas origens do pentecostalismo brasileiro que possibilitou essa acolhida dos mais antigos aos novos "crentes". Afinal, conforme visto por Paulo Rivera (RIVERA, 2005), o culto pentecostal tem muitas semelhanças com a festa justamente pelo caráter espontâneo de ambos e pela redução das normas que impõem à rigidez corporal. Nos dois momentos, da festa e do culto, há forte apelo aos sentidos que assumem um lugar de destaque. Ao contrário do protestantismo clássico, o pentecostalismo oferece maior possibilidade de manifestações corporais durante o culto.

O fato de oferecer uma parede na igreja para que os grafiteiros possam usar seu talento como forma de oração, além de garantir que estes jovens, por se sentirem aceitos, continuem a freqüentar o templo, faz com que muitos outros, atraídos pela possibilidade de experimentar a vida religiosa sem precisar abrir mão de sua identidade, passem a freqüentar as reuniões e desta forma criarem um espaço de descontração conectado a uma instituição religiosa.

De um lado estão jovens, negros, pobres, suburbanos, pertencentes ao movimento Hip Hop, conhecido por sua pouca visibilidade nos veículos de comunicação de massa e nas rádios comerciais; de outro, templos e pastores dispostos a oferecer a eles, que estão ávidos por conseguir, a possibilidade de enfim existirem, sem que seja preciso se "travestir" do que não são.

A estes jovens que já estão excluídos em muitas instâncias não é pedido que abram mão de seus valores estéticos, gostos musicais, turma de amigos e da linguagem com a qual se expressam e se reconhecem como iguais, o conhecido "dialeto da periferia". No lugar disto, reforçam muitos dos valores difundidos pelo próprio movimento Hip Hop, como manter distância das drogas e do álcool, e a valorização da auto-estima e da informação. A ênfase na informação é, inclusive, uma das características mais marcantes do Hip Hop, já que, segundo os jovens, há desconfiança com relação ao 
que é veiculado pela mídia, que representa para eles um instrumento de manutenção do "sistema".

Por seu lado, o pentecostalismo proporciona transformações nos fiéis através da vivência de experiências religiosas que redundam em capacidade de restaurar no indivíduo sua dignidade. Conforme visto nos estudos de Cecilia Mariz, o processo de conversão passa, muitas vezes, por fornecer aos fiéis ferramentas que os ajudem a se adaptar melhor às transformações ocorridas nas sociedades modernas. Através da conexão estabelecida entre a palavra da Bíblia e situações do cotidiano urbano e moderno, a religião pentecostal coloca muitos jovens em contato com um novo mundo de possibilidades (MARIZ, 1996).

Para estes jovens extremamente contaminados pela dinâmica do mundo moderno, tanto pelo seu lado perverso, quanto pelo seu lado atrativo, são poucas as exigências que lhes fazem as igrejas pentecostais, quanto a seu ingresso nelas. Basta "aceitar Jesus!" De uma maneira pragmática, interessa aos pastores que eles voltem na semana seguinte e, mais do que isto, que tragam outros jovens com eles.

E não são apenas as igrejas que se fortalecem com essa "abertura" do meio pentecostal à modernidade. Um mercado de bens religiosos gospel também se expande cada vez que um grupo como o "Ministério Galera de Cristo" se prepara para gravar um cd. Os sites, jornais, rádios e gravadoras estão de olho neste novo filão de mercado que, ao longo dos últimos anos, vem se mostrando um importante fator de presença dos evangélicos pentecostais na sociedade brasileira (ALMEIDA, R. \& RUMSTAIN, A, 2003; PINHEIRO, 2003). Situação que vem levantando a carreira artística de cantores e cantoras que estavam caindo no ostracismo, e criando a possibilidade - no caso de novos cantores, que estão investindo no ramo - destes já se lançarem para um público em constante crescimento e com disposição para valorizar os artistas religiosos. (DE PAULA, 2007, p.55-83). Há espaço para divulgação inclusive no meio secular, por exemplo, em concursos musicais, além da oportunidade de mostrarem seu trabalho, também podem conseguir recursos para arcar com os gastos iniciais do primeiro $\mathrm{CD}$ do grupo.

Ao longo das pesquisas, vimos que, embora a mídia hegemônica não mude significativamente a forma como retrata os jovens, negros, pobres, moradores da periferia; após a conversão religiosa, eles passam a contar com outros veículos, de grande força e penetração, como as rádios evangélicas, TVs, revistas e jornais, que os tornam verdadeiros ídolos, capazes de ditar moda e servir de modelo positivo para outros jovens como eles (NOVAES, 1999, 2003). 
Através desta relação muitos conseguem, então, re-construir sua auto-imagem e, a partir dela dar novo significado ao fato de serem negros, pobres e evangélicos. Ao longo deste trabalho, pudemos perceber através dos textos do Pastor Marcos Davi de Oliveira (OLIVEIRA, 2004), que a aproximação existente entre o universo dos rappers negros com o das igrejas pentecostais tinha fortes razões para existir, pois a história dos negros que vieram para o Brasil está fortemente ligada à religiosidade que enfatizava a dança, os ritmos, o batuque e a sensualidade. Esta postura foi recriminada pelas primeiras igrejas protestantes históricas, mas incentivada pelas igrejas pentecostais que propõem liberdade quase que ilimitada durante os cultos como forma de demonstrar manifestação do Espírito Santo ("que sopra onde quer").

O que podemos ver neste contexto é a presença de uma igreja em movimento, e de um movimento conectado a esta igreja, ambos em sintonia e afinidade com as mudanças do mundo contemporâneo. Constata-se aí um constante mimetismo com estilos da vida moderna, onde o label "de Cristo" ou "gospel" pode ser colado em qualquer produto ou atividade conferindo a este uma dignidade sagrada. Desta forma, também tornando este sagrado imanente e acessível aos indivíduos. Este processo revela uma complexidade, para além de uma simples banalização da religião reduzida à mercadoria, como apontaram alguns. Complexidade esta, ligada, como sugeriu Leila Amaral ao surgimento de comportamentos e religiosidades não-institucionais disseminadas em todos os domínios da vida moderna e em correspondência, sem prejuízo de sua "espiritualidade", com uma lógica de consumo, onde a principal mercadoria a ser veiculada são as identidades multi-situadas (AMARAL, 2003, p.97-108).

\section{REFERÊNCIAS}

ALMEIDA, Ronaldo. \& RUMSTAIN, Ariana. O gospel como sociabilidade religiosa. (Mimeo). GT 6: "Fronteiras do Sagrado: mutações na interface religião e sociedade". V Reunião de Antropologia do Mercosul, Florianópolis, 30 nov a 03 dez, 2003.

ALVIM, Rosilene \& PAIM, Eugênia. Os jovens suburbanos e a mídia: conceito e preconceitos. In: ALVIM, Rosilene; GOUVEIA, Patrícia (Org.). Juventude anos 90: conceitos, imagens, contextos. Rio de Janeiro: Contra Capa, 2000.

AMARAL, Leila. Deus é pop: sobre a radicalidade do trânsito religioso na cultura popular de consumo. In: SIEPIERSKI, Paulo D.; GIL, Benedito M. (Org.). Religião no Brasil: enfoques,dinâmicas e abordagens. São Paulo: Paulinas, 2003, p. 97-108. 
CAMPOS, Leonildo Silveira; GUTIÉRREZ Benjamin F. Na força do Espírito; os pentecostais na América Latina: um desafio às Igrejas históricas. São Paulo: AIPRAL, 1996.

CUNHA, Olívia Maria Gomes. "Fazendo a 'coisa certa': reggae, rastas e pentecostais em Salvador". Revista Brasileira de Ciências Sociais (RBCS) n.23, 1993.

DAYRELL. Juarez Tarcísio. O rap e o funk na socialização da juventude. Educação e Pesquisa, Belo Horizonte, v. 28, n. 1, p. 117-136, jan./jun. 2002.

A música entra em cena: o rap e o funk na socialização da juventude em Belo Horizonte. Belo Horizonte: Ed. UFMG, 2005.

DE PAULA, Robson. “'Os cantores do senhor’: três trajetórias em um processo de industrialização da música evangélica no país”.

GOMES, Nilma Lino. Corpo e cabelo como ícones de construção da beleza e da identidade negra nos salões étnicos de Belo Horizonte. (Tese de Doutorado), São Paulo: USP, 2002.

LOPES, A. C. The Transgression of the Racialized Subject in the Language of Brazilian HipHop. In: Annual ILASSA Student Conference, XXVII, Austin (Latin American network information center), 2007.

MAFRA, Clara. Os Evangélicos. Rio de Janeiro: Jorge Zahar Editores, 2001.

MARIANO, Ricardo. Neopentecostais: sociologia do novo pentecostalismo no Brasil. São Paulo: Loyola, 1999.

MARIZ, Cecília Loreto. Pentecostalismo e a luta contra a pobreza no Brasil. In: GUTIÉREZ, Benjamin F.; CAMPOS, Leonildo Silveira. Na força do Espírito; os pentecostais na América Latina, um desafio às igrejas históricas. São Paulo, AIPRAL, 1996. p. 169-189.

NOVAES, Regina Reyes. Errantes do novo milênio: salmos e versículos bíblicos no espaço público. In: BIRMAN, Patrícia (Org.). Religião e espaço público. Brasília/São Paulo: CNPQ/PRONEX/Attar Editorial, 2003. p. 25-39.

de Janeiro, v. 20, 1999, p. 65-92.

Ouvir para crer: os racionais e a fé na palavra. Religião e sociedade, Rio Juventude e religião: marcos geracionais e novas modalidades sincréticas. In: SANCHIS, Pierre (Org.). Fiéis \& cidadãos. Percursos de sincretismo no Brasil. Rio de Janeiro: 
Eduerj, 2001. p. 181-207.

NOVAES, Regina Reyes; MAFRA, Clara Cristina Jost. Juventude: Conflito e Solidariedade. Comunicações do ISER, Rio de Janeiro, n. 50, 1998.

OLIVEIRA, Marco David de. A religião mais negra do Brasil. São Paulo: Mundo Cristão, 2004.

OLIVEIRA, Roberto Cardoso de. Identidade étnica, identificação e manipulação. In: ---. Identidade, etnia e estrutura social. São Paulo: Pioneira, 1976.

PIERUCCI, Antônio Flávio. Ciências Sociais e religião: A religião como ruptura. In: TEIXEIRA, Faustino; MENEZES, Renata (Org.). As religiões no Brasil: continuidades e rupturas. Petrópolis: Vozes, 2006. p. 17-34.

PINHEIRO, Márcia Leitão. O sagrado e o lazer: o rap, o charme entre os evangélicos (Mimeo) GT 6: Fronteiras do Sagrado: mutações na interface religião e sociedade. In: Encontro Anual da RAM Reunião de Antropologia do Mercosul. Anais, Florianópolis, 30 nov a 03 dez, 2003.

Na 'pista' da fé: música, festa e outros encontros culturais entre os evangélicos do Rio de Janeiro. (Tese de Doutorado), Rio de Janeiro: IFCS-UFRJ, 2006.

QUINTÃO, Antônia Aparecida. A imagem das mulheres negras na televisão brasileira. In: CARRANÇA, F; BORGES, R. S. (Org.). Espelho infiel - o negro no jornalismo brasileiro. São Paulo: Imprensa Oficial do Estado de São Paulo e Sindicato dos Jornalistas do Estado de São Paulo, 2001.

RIVERA, Paulo Barrera. Festa, corpo e culto no pentecostalismo: Notas para uma antropologia do corpo no protestantismo latino-americano. Numen: revista de estudos e pesquisa da religião. Universidade Federal de Juiz de Fora. Juiz de Fora, v. 8, n. 2, 2ºm. 2005.

SOUTO, Jane. "Os outros lados do Funk carioca". In Hermano Vianna (org.). Galeras Cariocas: territórios de conflitos e de encontros culturais. RJ: Editora UFRJ, 2003, pp.58-92.

SOUZA, Jurandir de. A construção da Identidade a partir da dança e da religião. In: ---. Os Urbanitas, Revista de Antropologia Urbana, v. 1, jul. 2004. (Disponível na internet no URL; www.osurbanitas.org).

SOUZA, Marcos Alvito Pereira de. As cores de Acari: uma favela carioca. Rio de Janeiro: Editora FGV, 2001. 
